OPEN ACCESS

Edited by:

Naoaki Tsutsui,

Mie University, Japan

Reviewed by:

Radha Chaube,

Banaras Hindu University, India

Yilei Wang,

Jimei University, China

*Correspondence:

Chenchang Bao

baochenchang@nbu.edu.cn

Specialty section:

This article was submitted to

Aquatic Physiology,

a section of the journal

Frontiers in Marine Science

Received: 28 July 2021

Accepted: 21 September 2021

Published: 08 October 2021

Citation:

Yang Y, Zhang P, Cui Z and Bao C

(2021) Bone Morphogenetic Protein 2

Is Involved in Oocyte Maturation

Through an Autocrine/Paracrine

Pathway in Scylla paramamosain.

Front. Mar. Sci. 8:748928.

doi: 10.3389/fmars.2021.748928

\section{Bone Morphogenetic Protein 2 Is Involved in Oocyte Maturation Through an Autocrine/Paracrine Pathway in Scylla paramamosain}

\author{
Yanan Yang, Peng Zhang, Zhaoxia Cui and Chenchang Bao* \\ School of Marine Science, Ningbo University, Ningbo, China
}

Ovary-secreted autocrine/paracrine factors play important roles in regulating oocyte maturation via the autocrine/paracrine pathway. This study aimed to evaluate the functions of bone morphogenetic protein 2 (BMP2) in oocyte maturation and communication between follicle cells and oocytes. In our study, we first identified BMP2 from the mud crab Scylla paramamosain. Quantitative real-time PCR showed that BMP2 was detected in diverse tissues, notably in the ovary, stomach and gill. The expression levels of BMP2 transcripts increased during vitellogenesis. Spatial expression of BMP2 and receptors in the ovary revealed that BMP2 was exclusively detected in oocytes, whereas the receptors were expressed in both follicle cells and oocytes. RNAi tests revealed that the expression of cyclin B first decreased at $2 \mathrm{~h}$ and then increased at $4 \mathrm{~h}$ after BMP2 knockdown. These combined findings suggest that BMP2 may promote oocyte maturation through an autocrine/paracrine pathway in S. paramamosain. Keywords: bone morphogenetic protein 2, oocyte maturation, autocrine/paracrine pathway, oocytes and follicle
cells, mud crab

\section{INTRODUCTION}

In vertebrates, oocyte maturation is a complicated mutual interaction between extraovarian and intraovarian signals (Ge, 2005; Emori and Sugiura, 2014). In vertebrates, oocyte maturation is generally activated by luteinizing hormone ( $\mathrm{LH})$, which is produced and secreted from the pituitary (Nagahama and Yamashita, 2008). In addition to this classical endocrine pathway, growing evidence suggests that many intraovarian autocrine/paracrine factors, such as transforming growth factor $\beta$ (TGF $\beta$ ) and epidermal growth factor (EGF), play critical roles in oocyte maturation via the autocrine/paracrine pathway (Ge, 2005; Clelland and Peng, 2009). Bone morphogenetic protein (BMP), a member of the TGF $\beta$ superfamily, has been demonstrated to play intraovarian autocrine/paracrine roles in development and follicular formation (Glister et al., 2004; Knight and Glister, 2006). For example, rat BMP9 plays an autocrine role in regulating steroidogenesis in ovarian granulosa cells (Hosoya et al., 2015). BMP2 is located in granulosa cells, and its receptors are expressed in both granulosa cells and oocytes. BMP2 stimulates steroidogenesis in granulosa cells through an autocrine pathway (Inagaki et al., 2009). 
The mud crab Scylla paramamosain (Crustacea: Decapoda: Brachyura) is an economically important and nutritious crab species in China and South Asia. Ovarian development in S. paramamosain has been divided into undeveloped (stage I), pre-vitellogenic (stage II), early vitellogenic (stage III), late vitellogenic (stage IV), and mature (stage V) stages (Bao et al., 2018). In the late vitellogenic stage, the size of the oocyte nucleus reaches a maximum of almost $40 \mu \mathrm{m}$, the oocyte germinal vesicle (GV) becomes obvious, and the oocytes are usually arrested at the prophase of the first meiosis (Yang et al., 2019). Meiotic arrest resumes by a stimulus, and the first clear sign of meiosis initiation is germinal vesicle breakdown (GVBD) (Eppig, 1982). It has been reported that oocytes in the GV stage could be induced to mature by 5-HT (Yang et al., 2019). Recent studies found that short neuropeptide $F$ (sNPF), BMP7 and BMP9/10 can play roles as intraovarian autocrine/paracrine factors by regulating oocyte maturation in mud crabs (Bao et al., 2018; Yang et al., 2018, 2021). As a paracrine factor, BMP7 plays a potentially inhibitory role in oocyte maturation, which is induced by $17 \alpha, 20 \beta$-dihydroxyprogesterone (DHP) (Shu et al., 2016; Yang et al., 2018). However, the effects of other autocrine/paracrine factors on oocyte maturation are still unknown.

In this study, we focused on the effects of BMP2 on oocyte maturation. We analyzed the expression patterns of ligand and receptors of $\mathrm{BMP} 2$ in follicle cells and oocytes, then characterized BMP2 expression at the GV and GVBD stages. We reveal the function of BMP2 in oocyte maturation via an autocrine/paracrine pathway in $S$. paramamosain.

\section{MATERIALS AND METHODS}

\section{Experimental Animals}

According to the morphological and histological features, the mud crab vitellogenesis was classified into the pre-vitellogenic stage, the early vitellogenic stage and the late vitellogenic stage (Huang et al., 2014). Crabs were purchased from the eight market in Xiamen, Fujian Province, China. All crabs were under normal physiological conditions without any induction or treatment in this study. Prior to dissections, crabs were anaesthetized on ice for $30 \mathrm{~min}$. Our study did not involve endangered or protected species.

\section{Sequence Analysis of Bone Morphogenetic Protein 2}

The sequence of BMP2 cDNA was obtained from transcriptome data (NCBI SRA database: SRR3086589, SRR3086590, and SRR3086592) and was verified by DNA sequencing. The obtained BMP2 cDNA sequence was compared with the NCBI nucleotide database using the NCBI BLAST tool ${ }^{1}$. The deduced amino acid sequence was translated using DNAStar BioEdit software. Then, multiple sequence alignments were performed using the LaTEX TexShade package to present the conserved sequence motifs and show the LOGO.

\footnotetext{
${ }^{1}$ http://blast.ncbi.nlm.nih.gov/Blast.cgi
}

\section{RNA Extraction and cDNA Synthesis}

Total RNA was extracted using TRIzol RNA isolation reagent (Invitrogen) according to the manufacturer's instructions. The concentration and quality of RNA were determined using a NanoOne spectrophotometer. First-strand cDNA was synthesized from $2 \mu \mathrm{g}$ of total RNA using the PrimeScript ${ }^{\mathrm{TM}} \mathrm{RT}$ reagent kit with gDNA Eraser (TaKaRa).

\section{Tissue Distribution and Expression Profile of Bone Morphogenetic Protein 2}

Total RNA was isolated from various tissues, including the eyestalk ganglion, cerebral ganglion, thoracic ganglion, ovary, stomach, hepatopancreas and gill. Fluorescence quantitative real-time PCR (qRT-PCR) was carried out to detect the mRNA distribution in different tissues and the temporal expression profile in the ovary. Gene-specific primers for BMP2 (Table 1) were used to amplify the corresponding products. The housekeeping gene $\beta$-actin (GenBank ID: GU992421) was used to compare the relative expression levels of BMP2 in the samples. qRT-PCR measurements were performed using the Applied Biosystems 7500 Real-time PCR System (Carlsbad, CA United States) version 2.4 software. qRT-PCR was carried out in a total volume of $20 \mu \mathrm{l}$, containing $10 \mu \mathrm{l}$ of SYBR Premix Ex $\mathrm{Taq}^{\mathrm{TM}}$ (Takara), $0.4 \mu \mathrm{l}$ of ROX ${ }^{\mathrm{TM}}$ Reference Dye (Takara), $0.5 \mu \mathrm{l}$ of each primer $(10 \mathrm{mM}), 2 \mu \mathrm{l}$ of the diluted cDNA and $6.6 \mu \mathrm{l}$ of $\mathrm{ddH}_{2} \mathrm{O}$. The thermal profile for qRT-PCR was $30 \mathrm{~s}$ at $95^{\circ} \mathrm{C}$ for 1 cycle, $5 \mathrm{~s}$ at $95^{\circ} \mathrm{C}, 30 \mathrm{~s}$ at $56^{\circ} \mathrm{C}$, and $30 \mathrm{~s}$ at $72^{\circ} \mathrm{C}$ for 42 cycles. All experiments were repeated independently at least three times.

In addition, the temporal expression pattern of BMP2 was estimated using qRT-PCR as described above.

\section{Separation of Oocytes and Follicle Cells}

Follicle cells were separated from the corresponding oocytes as previously described (Yang et al., 2018). Ovaries at the late

TABLE 1 | Details of primers for this study.

\begin{tabular}{|c|c|c|}
\hline Gene name & Primer sequence $\left(5^{\prime}-3^{\prime}\right)$ & Purpose \\
\hline \multirow[t]{2}{*}{ Cyclin B } & GACGCTCTTCCTCACTGTTGG & qRT-PCR \\
\hline & GTCTGGGCAAACCATCTCCTC & qRT-PCR \\
\hline \multirow[t]{2}{*}{ BMP2 } & GTGAGAGCACGGACCAAAGA & $\begin{array}{l}\text { Semi quantitative PCR and } \\
\text { qRT-PCR }\end{array}$ \\
\hline & ACGCTGCACTACACCTTTGT & $\begin{array}{l}\text { Semi quantitative PCR and } \\
\text { qRT-PCR }\end{array}$ \\
\hline \multirow[t]{2}{*}{ BMP2 } & TGCСACTCGCTCСTCTGA & RNAi \\
\hline & CTCGGCTITCCCAGCTACCTAT & RNAi \\
\hline \multirow[t]{2}{*}{ BMPRIB } & TCTTCCTCCCTTGCTGACC & Semi quantitative PCR \\
\hline & GGTCAGGTGGCACAAGGTCA & Semi quantitative PCR \\
\hline \multirow[t]{2}{*}{ BMPRII } & GGTGGTGCGAAACAAAGCC & Semi quantitative PCR \\
\hline & TTGCCTCAGCATCGTAGTCCC & SEMI quantitative PCR \\
\hline \multirow[t]{2}{*}{ GFP } & TGGGCGTGGATAGCGGTTG & qRT-PCR \\
\hline & GGTCGGGGTAGCGGCTGAAG & qRT-PCR \\
\hline \multirow[t]{2}{*}{$\beta$-actin } & GAGCGAGAAATCGTTCGTGAC & $\begin{array}{l}\text { Semi quantitative PCR and } \\
\text { qRT-PCR }\end{array}$ \\
\hline & GGAAGGAAGGCTGGAAGAGAG & $\begin{array}{l}\text { Semi quantitative PCR and } \\
\text { qRT-PCR }\end{array}$ \\
\hline
\end{tabular}


vitellogenic stage were dissected from the crabs and then placed in a plastic culture dish with modified crab saline $(11.3 \mathrm{mM}$ $\mathrm{KCl}, 440 \mathrm{mM} \mathrm{NaCl}, 26 \mathrm{mM} \mathrm{MgCl} 2,13.3 \mathrm{mM} \mathrm{CaCl}_{2}, 23 \mathrm{mM}$ $\mathrm{Na}_{2} \mathrm{SO}_{4}, 10 \mathrm{mM}$ HEPES, $\mathrm{pH}$ 7.4). Follicle layers were gently removed with fine forceps. The denuded oocytes and separated follicle layers were collected for RNA extraction, with three biological replicates.

\section{Expression Pattern of Bone Morphogenetic Protein 2 and Receptors in the Ovary by Semiquantitative PCR}

Semiquantitative PCR was used to determine the expression profiles of BMP2 and BMPRs in the ovary, follicle cells and denuded oocytes. The specific primers of BMPRs for PCR were designed according to the cDNA sequences (GenBank: KU985444 and KU985443). Negative ( $\beta$-actin) and blank controls (no template) were carried with the target gene together. Semiquantitative PCR was carried out in a volume of $25 \mu 1$ containing $12.5 \mu$ l of $2 \times$ Premix Ex Taq II (Takara), $2 \mu$ l of cDNA template, $1 \mu \mathrm{M}$ each primer and $8.5 \mu \mathrm{l}$ of $\mathrm{H}_{2} \mathrm{O}$. The thermal profile for the PCR was $3 \mathrm{~min}$ at $95^{\circ} \mathrm{C}$ for $1 \mathrm{cycle}, 30 \mathrm{~s}$ at $94^{\circ} \mathrm{C}, 30 \mathrm{~s}$ at $56^{\circ} \mathrm{C}$, and $30 \mathrm{~s}$ at $72^{\circ} \mathrm{C}$ for 38 cycles, followed by an extension at $72^{\circ} \mathrm{C}$ for $10 \mathrm{~min}$. The PCR products were analyzed by $1.5 \%$ agarose gel electrophoresis. PCR was conducted in quadruplicate for each individual sample. All the primers were listed in Table 1.

\section{Expression of Bone Morphogenetic Protein 2 in the Germinal Vesicle and Germinal Vesicle Breakdown Stages}

Ovaries at the late vitellogenic and mature stages were selected to obtain oocytes in the GV and GVBD stages. Briefly, oocytes in the GV and GVBD stages were determined using a clearing solution (formaldehyde, ethanol, acetic acid, 30:42:1) followed by microscopic examination. Four biological replicates were used for BMP2 detection. qRT-PCR was carried out as described above.

\section{Effect of Bone Morphogenetic Protein 2 on Cyclin B Expression in vitro}

We first designed specific primers to amplify the sequences of BMP2 and the green fluorescent protein (GFP) gene (as an exogenous control gene) (Table 1). Then, the pure DNA templates were used to synthesize the dsRNA with T7 and SP6 polymerases. The remaining DNA template in dsRNA solution was digested with RNase-free DNase I (TaKaRa). Finally, the quality, concentration and integrity of dsRNA were detected using a NanoOne spectrophotometer and agarose gel electrophoresis.

The dissection and treatment of ovarian explants were carried out as described in a previous study (Liu et al., 2019). Female crabs at the late vitellogenic stage were anaesthetized for $15 \mathrm{~min}$ on ice and sterilized in $75 \%$ ethanol for $10 \mathrm{~min}$. Then, ovarian tissues at the GV stage were dissected and washed 6 times with modified crab saline. Subsequently, the ovary samples were cut into 50-mg fragments and then placed in a well of a 24-well tissue culture plate with $1.5 \mathrm{ml} 2 \times \mathrm{L} 15$ medium containing streptomycin (300 IU ml-1) and penicillin G (300 IU ml-1).
The experiment included three treatments, namely, dsRNA for BMP2 and GFP (negative control), as well as a blank control (no dsRNA), with each treatment performed in four replicates $(n=4)$. The ovarian explants were cultured with dsRNA at $25^{\circ} \mathrm{C}$ and then collected at $1,2,4,6$, and $8 \mathrm{~h}$ for gene expression analysis to determine the effect of dsRNA. After the target gene was silenced, the expression of cyclin B was analyzed by qRT-PCR, as described above, using the primers listed in Table $\mathbf{1}$.

\section{Data Analysis}

BMP2 expression relative to the control was determined by the $2^{-\Delta \Delta \mathrm{Ct}}$ method. All data are presented as the mean $\pm \mathrm{SD}$. Statistical analyses were performed using SPSS 20 software. Data were normally distributed, as assessed with normality tests (Shapiro-Wilk test). Independent samples $t$-tests were used to analyze BMP2 expression between follicle cells and oocytes and the GV and GVBD stages. Data for different vitellogenic stages and RNAi experiments were first subjected to Levene's test for testing the homogeneity of variances and then subjected to one-way analysis of variance (ANOVA) with Scheffés method post hoc analysis. $P$-values less than 0.05 were considered statistically significant.

\section{RESULTS}

\section{Sequence of Bone Morphogenetic Protein 2 cDNA}

In the transcriptome data of $S$. paramamosain, a 2,594bp transcript was found to encode BMP2. The nucleotide sequence showed high conservation to orthologs of other known BMP2 transcripts from different decapods, especially from the Chinese mitten crab Eriocheir sinensis. The BMP2 transcript was composed of a 1,224-bp open reading frame (ORF), a 580-bp $5^{\prime}$ untranslated region and a 790-bp $3^{\prime}$-untranslated region. This ORF encoded a 407-aa protein, and the calculated molecular mass was $46.4 \mathrm{kDa}$. A BLAST search of the $S$. paramamosain BMP2 protein sequence showed high scoring identities to BMP2 proteins from other species; the highest score was an $88 \%$ identity to the amino acid sequence from the swimming crab Portunus trituberculatus. The alignment of the deduced amino acid sequences in different species is shown in Figure 1.

\section{Tissue Distribution and Expression Profile of Bone Morphogenetic Protein 2}

qRT-PCR was used to detect the expression levels of BMP2 in seven tissues (eyestalk, cerebral ganglia, thoracic ganglia, ovary, stomach, hepatopancreas and gill) of S. paramamosain (Figure 2). The results indicated that BMP2 was detected in various tissues. A predominant transcript expression level of BMP2 was detected in the ovary, stomach and gill (Figure 2).

To determine whether BMP2 acts on ovarian development, qRT-PCR was employed to detect its expression in different vitellogenic stages. As demonstrated in Figure 3, BMP2 was increased from pre-vitellogenic stage to the early and late vitellogenic stages. 


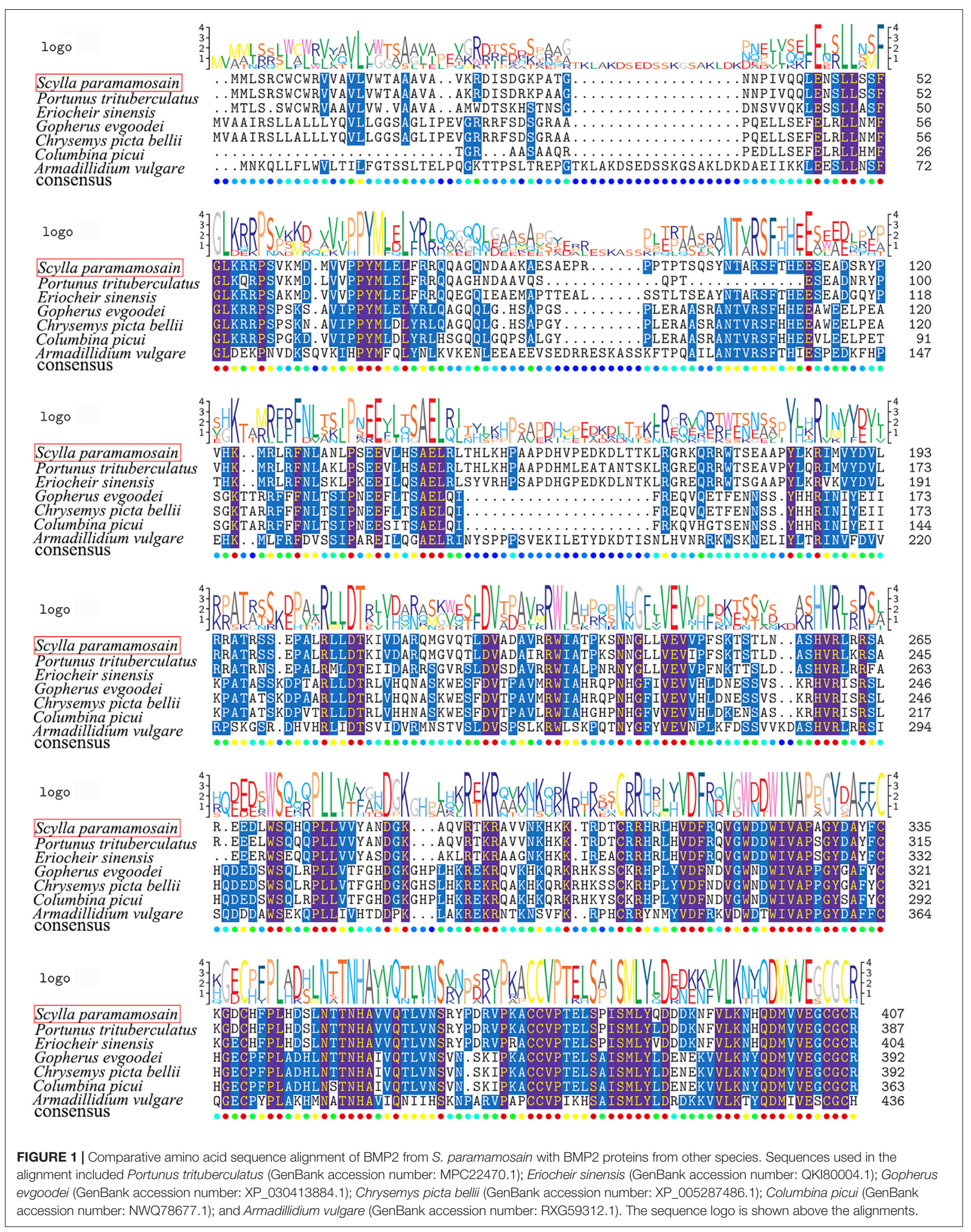




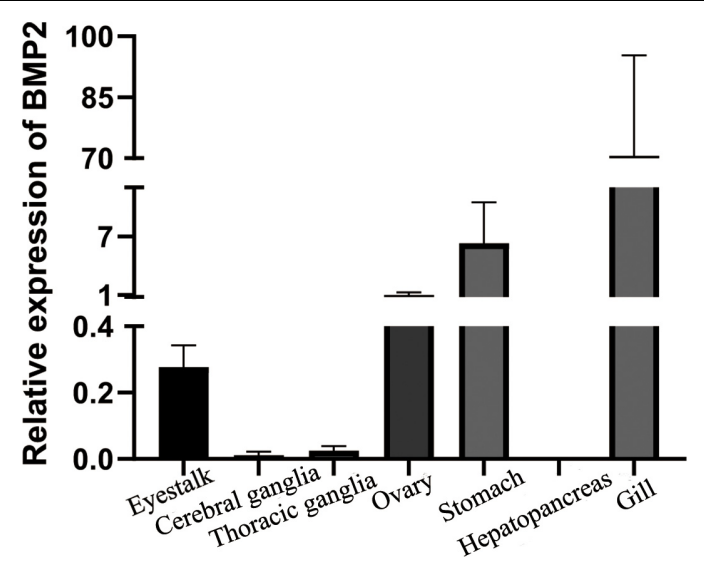

FIGURE 2 | Tissue distribution of BMP2 in S. paramamosain. Expression of $\beta$-actin was used as internal control. The relative expression of BMP2 was analyzed by qRT-PCR.

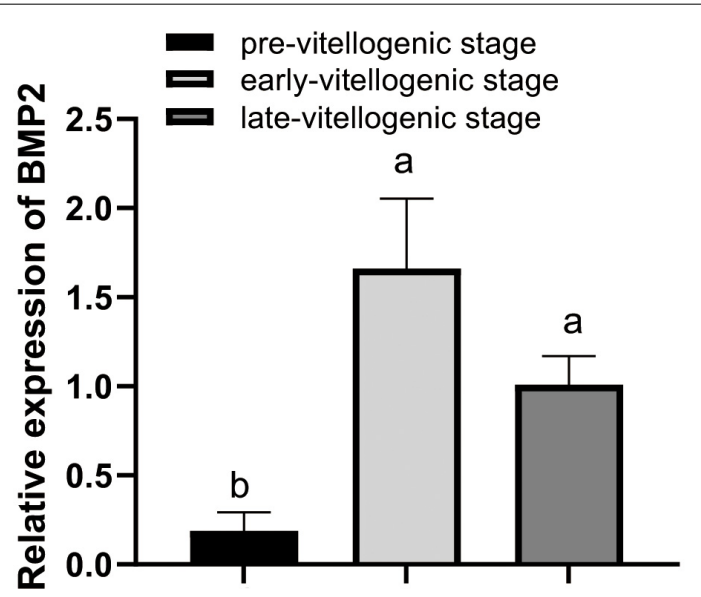

Different vitellogenic stages

FIGURE 3 | Temporal expression profile of $S$. paramamosain BMP2 in ovarian development. The expression level of BMP2 was investigated by qRT-PCR and normalized to $\beta$-actin. The relative expression abundances are presented as the means $\pm \operatorname{SD}(n=4)$. Different letters above the bars demonstrate significant differences between different vitellogenic stages $(P<0.05)$.

\section{Spatial Expression of Bone Morphogenetic Protein 2 and BMPRs in the Ovary}

We used semiquantitative PCR to determine the mRNA expression level of BMP2 and its receptors in follicle cells and oocytes derived from the ovaries at the late vitellogenic stage (stage IV). The results revealed that BMP2 and its receptors show a distinctive distribution pattern in follicle cells and oocytes. BMP2 was exclusively detected in oocytes (Figure 4). Unlike the ligand, the receptors bone morphogenetic protein receptor IB (BMPRIB) and bone morphogenetic protein receptor II (BMPRII) were located in both follicle cells and oocytes (Figure 4). $\beta$-actin (used as the housekeeping gene) was concurrently tested in all cDNA templates, while no signal was detected in the blank control (distilled water was used to serve as the template during PCR).

\section{Role of Bone Morphogenetic Protein 2 in Oocyte Maturation}

To research the function of BMP2 in oocyte maturation, the expression level of BMP2 was detected in the GV and GVBD stages. BMP2 showed a higher expression level in the GV stage (Figure 5). Afterward, we used dsRNAs to silence BMP2 in ovaries in the GV stage and analyzed the expression patterns using $\mathrm{qRT}-\mathrm{PCR}$. The results revealed that BMP2 was significantly silenced at 1 and $2 \mathrm{~h}$ (Figure 6A). Then, we analyzed the expression of cyclin $\mathrm{B}$, which was decreased first at $2 \mathrm{~h}$ and then increased at $4 \mathrm{~h}$ (Figure 6B).

\section{DISCUSSION}

In our study, we cloned BMP2 from S. paramamosain, which was similar to the sequence of BMP2 in E. sinensis (Yang et al., 2020). Similar to BMP7 in the mud crab, a TGF-b propeptide is located in the BMP2 N-terminus region (Shu et al., 2016). The C-terminus of BMP2 has a TGF- $\beta$-DPP domain that is found in Drosophila melanogaster protein decapentaplegic (Dpp) and is responsible for development (Allendorph et al., 2007). Thus, data from the sequence of BMP2 indicated that this sequence is a member of the BMP family (Xiao et al., 2007).

Higher expression levels of BMP2 were observed in the gill and stomach of S. paramamosain. BMP2 is also expressed at a high level in the gill of E. sinensis (Yang et al., 2020). In crustaceans, a thin chitin layer covers the external surface of the gill (Flemister, 1959), and the gastric mill is a masticating apparatus that is a part of the stomach and also contains a chitin layer (Yonge, 1926). The higher expression levels of BMP2 in the gill and stomach implied that BMP2 may be related to chitin formation. In mammals, BMP2 is a vital protein for bone formation and development (Rosen, 2009). However, crustaceans have a chitin carapace instead of the bones found in mammals (RodriguezChanfrau et al., 2019). In crustaceans, BMP2 may be related to chitin formation. Moreover, BMP2 was also highly expressed in the ovary. Higher expression levels of some BMPs in the ovary have been identified in both mammals and crustaceans (Lima et al., 2012; Shu et al., 2016) and are responsible for ovary development and oocyte maturation (Peng et al., 2009; Yang et al., 2018).

To determine the relationship between BMP2 and reproduction, the expression pattern of BMP2 was subsequently analyzed during ovarian development. A significantly low expression was observed at the pre-vitellogenic stage, while relatively abundant expression of BMP2 was observed in the early vitellogenic and late vitellogenic stages, indicating that BMP2 might be involved in vitellogenesis and late ovarian development. This finding was obviously incompatible with the expression profile of BMP2b in zebrafish, which showed a peak at the pre-vitellogenic stage and declined steadily toward the end of folliculogenesis ( $\mathrm{Li}$ and Ge, 2011). The tendencies of BMP2 


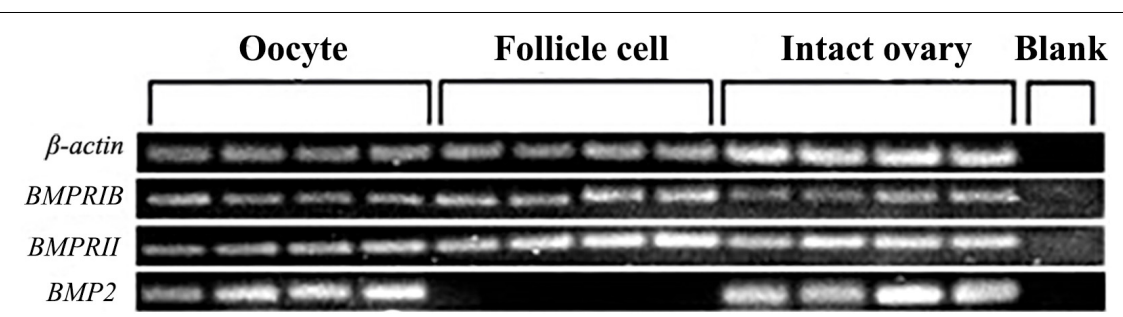

FIGURE 4 | Localization of BMP2 and two BMPRs in the ovary. BMP2 transcript was exclusively expressed in the oocytes. In contrast, two BMP receptors (BMPRIB and BMPRII) were located on both follicle cells and denuded oocytes. The housekeeping gene ( $\beta$-actin) was detected in each sample, while no signal was detected in the blank control.

expression at different vitellogenic stages of the mud crab were also different from other BMP members, such as BMP7 in the mud crab and growth differentiation factor 9 (GDF9) in ricefield eel (He et al., 2012; Shu et al., 2016). It is possible that this discrepancy was due to species diversity. The expression profile of BMP2, combined with the expression levels of BMP receptors, was significantly higher in the early and late vitellogenic stages (Shu et al., 2016), suggesting a potential role for BMP2 in ovarian maturation. BMP2 and other BMPs have also been reported to be involved in ovarian maturation in other species, such as BMP2 in buffalo and BMP15 in zebrafish (Peng et al., 2009; Rajesh et al., 2018).

BMPs, as members of the TGF $\beta$ superfamily, act on oocyte maturation in an autocrine/paracrine manner (Ge, 2005; Clelland and Peng, 2009). Similar to the TGF $\beta$ superfamily, BMPs have been shown to act via two types of BMPRI (BMPRIA and BMPRIB) and BMPRII (Wang and Roy, 2009). In this study, we detected the spatial expression of BMP2

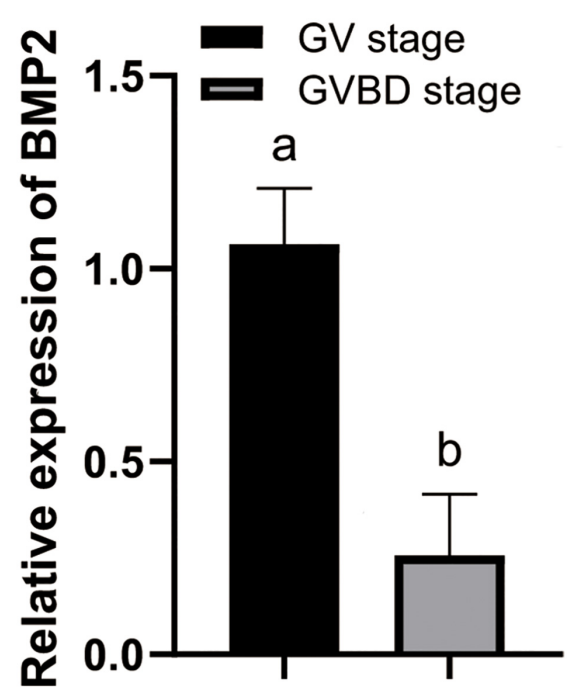

Different stages

FIGURE 5 | Temporal expression profiles of BMP2 at the GV and GVBD stages. The relative expression levels are shown as the means $\pm \operatorname{SD}(n=4)$. Different letters above the bars demonstrate significant differences between the oocytes at the GV and GVBD stages $(P<0.05$, independent $t$-test). and BMPRs in the ovary. BMP2 was exclusively expressed in oocytes, and receptors were detected in both follicle cells and oocytes. The localization of BMP2 and BMPRs revealed that there was a potential autocrine/paracrine pathway in the mud crab ovary, as in the study of $S$. paramamosain BMP7 (Yang et al., 2018). These findings were consistent with reports from mammals (Brankin et al., 2005; Inagaki et al., 2009). For example, BMP2 was found in granulosa

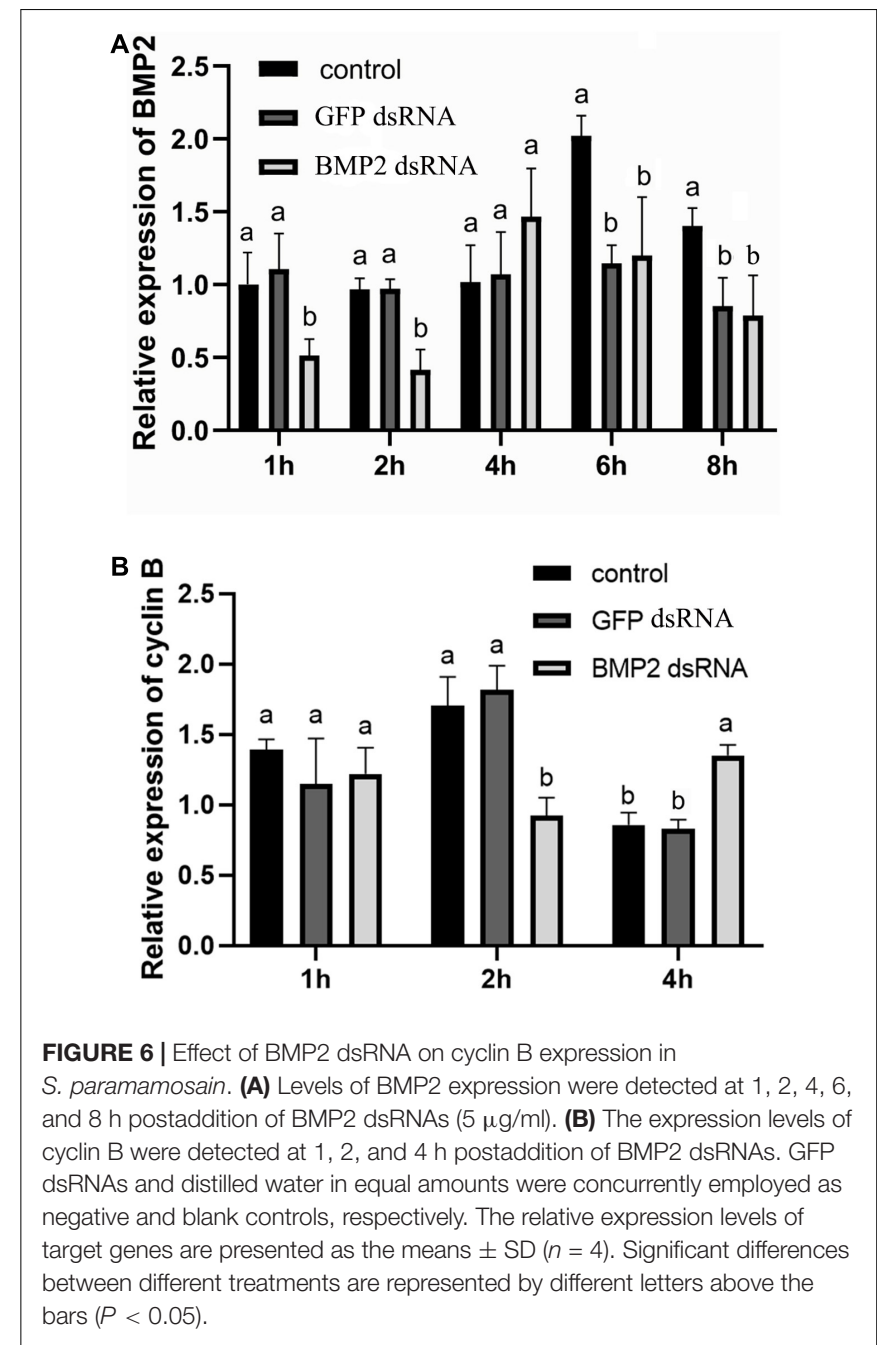


cells, receptors were found in oocytes and granulosa cells of rats, and $\mathrm{BMP} 2$ can regulate estradiol production in granulosa cells in the autocrine pathway (Inagaki et al., 2009). Porcine BMP2 and BMPRs were observed in granulosa cells and oocytes, and BMP2 in oocytes acted in a paracrine manner to suppress progesterone production in granulosa cells (Brankin et al., 2005). Our results suggested that BMP2 may be involved in similar autocrine/paracrine signaling in S. paramamosain.

To investigate the role of BMP2 in oocyte maturation, an RNAi experiment was carried out to knock down the expression of BMP2. The expression level of cyclin B was decreased first at $2 \mathrm{~h}$, which indicated that cyclin $\mathrm{B}$ might be regulated by BMP2. However, the expression level of cyclin B was increased at $4 \mathrm{~h}$ after the addition of BMP2 dsRNA. There is much crossreactivity among different BMP ligands and type-I receptors (Shimasaki et al., 2004). It could be speculated that the BMP2 deficiency was offset by other BMP subtypes, which was similar to the study of BMP7 in S. paramamosain (Yang et al., 2018). During oocyte maturation, BMP2 regulated the expression of cyclin B, with higher expression levels evident at the GV stage than at the GVBD stage. These results were similar to the study of BMP9/10 in mud crabs, which also showed higher expression levels in the GV stage and regulated cyclin A and cyclin B (Yang et al., 2021). In our previous study, we found that BMP7 was secreted from follicle cells and suppressed DHP-induced oocyte maturation in mud crabs (Yang et al., 2018), whereas BMP2 secreted from oocytes may promote oocyte maturation. BMPs play vital roles in regulating follicle maturation in vertebrates (Wang et al., 2015). As demonstrated in previous studies, BMP6 can promote the maturation of mouse preantral follicle maturation, and GDF9 and BMP15 can regulate canine cumulus maturation (Wang et al., 2015; Ramirez et al., 2020). In porcine oocytes, the expression levels of BMP15 and GDF9 were significantly increased at GVBD compared with GV stages and participated in oocyte maturation (Lin et al., 2014). Consequently, we hypothesize that BMP2 plays a critical role in oocyte maturation of $S$. paramamosain, possibly through an autocrine/paracrine pathway.

\section{REFERENCES}

Allendorph, G. P., Isaacs, M. J., Kawakami, Y., Izpisua Belmonte, J. C., and Choe, S. (2007). BMP-3 and BMP-6 structures illuminate the nature of binding specificity with receptors. Biochemistry 46, 12238-12247. doi: 10.1021/ bi700907k

Bao, C. C., Yang, Y. N., Huang, H. H., and Ye, H. H. (2018). Inhibitory role of the mud crab short neuropeptide $\mathrm{F}$ in vitellogenesis and oocyte maturation via autocrine/paracrine signaling. Front. Endocrinol. 9:390. doi: 10.3389/fendo. 2018.00390

Brankin, V., Quinn, R. L., Webb, R., and Hunter, M. G. (2005). Evidence for a functional bone morphogenetic protein (BMP) system in the porcine ovary. Domest. Anim. Endocrinol. 28, 367-379. doi: 10.1016/j.domaniend.2005.01.001

Clelland, E., and Peng, C. (2009). Endocrine/paracrine control of zebrafish ovarian development. Mol. Cell. Endocrinol. 312, 42-52. doi: 10.1016/j.mce.2009.04.009

Emori, C., and Sugiura, K. (2014). Role of oocyte-derived paracrine factors in follicular development. Anim. Sci. J. 85, 627-633. doi: 10.1111/asj.12200

Eppig, J. J. (1982). The relationship between cumulus cell-oocyte coupling, oocyte meiotic maturation, and cumulus expansion. Dev. Biol. 89, 268-272. doi: 10. 1016/0012-1606(82)90314-1

\section{CONCLUSION}

In our study, we first identified BMP2 from the mud crab Scylla paramamosain. The spatial expression of BMP2 and receptors in ovary revealed that, the BMP2 might be an autocrine/paracrine factor. The expression of BMP2 mRNA increased along the ovarian development implied that BMP2 was probably involved in vitellogenesis and late ovarian development. Furthermore, the expression of cyclin B was decreased after the BMP2 knockdown. These combined findings suggest that BMP2 may promote oocyte maturation through an autocrine/paracrine pathway in S. paramamosain.

\section{DATA AVAILABILITY STATEMENT}

The datasets presented in this study can be found in online repositories. The names of the repository/repositories and accession number(s) can be found below: https://www.ncbi. nlm.nih.gov/genbank/, KU985443; https:/www.ncbi.nlm.nih. gov/genbank/, KU985444; https://www.ncbi.nlm.nih.gov/, SRR3086589; https://www.ncbi.nlm.nih.gov/, SRR3086590; https://www.ncbi.nlm.nih.gov/, SRR3086592.

\section{AUTHOR CONTRIBUTIONS}

YY: conceptualization, sample collection, experiment, and writing-original draft. PZ: experiment. ZC: supervision. CB: sample collection, editing, and supervision. All authors contributed to the article and approved the submitted version.

\section{FUNDING}

This study was supported by the National Natural Science Foundation of China (grant no: 31902350) and the K. C. Wong Magna Fund in Ningbo University.

Flemister, S. C. (1959). Histophysiology of gill and kidney of crab Ocypode albicans. Biol. Bull. 116, 37-48. doi: 10.2307/1539154

Ge, W. (2005). Intrafollicular paracrine communication in the zebrafish ovary: the state of the art of an emerging model for the study of vertebrate folliculogenesis. Mol. Cell. Endocrinol. 237, 1-10. doi: 10.1016/j.mce.2005.03.012

Glister, C., Kemp, C. F., and Knight, P. G. (2004). Bone morphogenetic protein (BMP) ligands and receptors in bovine ovarian follicle cells: actions of BMP4, -6 and -7 on granulosa cells and differential modulation of Smad-1 phosphorylation by follistatin. Reproduction 127, 239-254. doi: 10.1530/rep.1. 00090

He, Z., Wu, Y., Xie, J., Wang, T., Zhang, L., and Zhang, W. (2012). Growth differentiation factor 9 (GDF9) was localized in the female as well as male germ cells in a protogynous hermaphroditic teleost fish, ricefield eel Monopterus albus. Gen. Comp. Endocrinol. 178, 355-362. doi: 10.1016/j.ygcen.2012.06.016

Hosoya, T., Otsuka, F., Nakamura, E., Terasaka, T., Inagaki, K., TsukamotoYamauchi, N., et al. (2015). Regulatory role of BMP-9 in steroidogenesis by rat ovarian granulosa cells. J. Steroid Biochem. Mol. Biol. 147, 85-91. doi: 10.1016/ j.jsbmb.2014.12.007

Huang, X. S., Ye, H. H., Huang, H. Y., Yang, Y. N., and Gong, J. (2014). An insulinlike androgenic gland hormone gene in the mud crab, Scylla paramamosain, 
extensively expressed and involved in the processes of growth and female reproduction. Gen. Comp. Endocrinol. 204, 229-238. doi: 10.1016/j.ygcen.2014. 06.002

Inagaki, K., Otsuka, F., Miyoshi, T., Yamashita, M., Takahashi, M., Goto, J., et al. (2009). p38-Mitogen-activated protein kinase stimulated steroidogenesis in granulosa cell-oocyte cocultures: role of bone morphogenetic proteins 2 and 4. Endocrinology 150, 1921-1930. doi: 10.1210/en.2008-0851

Knight, P. G., and Glister, C. (2006). TGF- $\beta$ superfamily members and ovarian follicle development. Reproduction 132, 191-206. doi: 10.1530/rep.1.01074

Li, C. W., and Ge, W. (2011). Spatiotemporal expression of bone morphogenetic protein family ligands and receptors in the zebrafish ovary: a potential paracrine-signaling mechanism for oocyte-follicle cell communication. Biol. Reprod. 85, 977-986. doi: 10.1095/biolreprod.111.092239

Lima, I. M. T., Brito, I. R., Rossetto, R., Duarte, A. B. G., Rodrigues, G. Q., Saraiva, M. V. A., et al. (2012). BMPRIB and BMPRII mRNA expression levels in goat ovarian follicles and the in vitro effects of BMP-15 on preantral follicle development. Cell Tissue Res. 348, 225-238. doi: 10.1007/s00441-012-1361-4

Lin, Z. L., Li, Y. H., Xu, Y. N., Wang, Q. L., Namgoong, S., Cui, X. S., et al. (2014). Effects of growth differentiation factor 9 and bone morphogenetic protein 15 on the in vitro maturation of porcine oocytes. Reprod. Domest. Anim. 49, 219-227. doi: $10.1111 /$ rda.12254

Liu, A., Liu, F., Shi, W. Y., Huang, H. Y., Wang, G. Z., and Ye, H. H. (2019). C-type allatostatin and its putative receptor from the mud crab serve an inhibitory role in ovarian development. J. Exp. Bio. 222:21. doi: 10.1242/jeb.207985

Nagahama, Y., and Yamashita, M. (2008). Regulation of oocyte maturation in fish. Dev. Growth Differ. 50, s159-s219. doi: 10.1111/j.1440-169X.2008.01019.x

Peng, C., Clelland, E., and Tan, Q. (2009). Potential role of bone morphogenetic protein-15 in zebrafish follicle development and oocyte maturation. Comp. Biochem. Physiol. A Mol. Integr. Physiol. 153, 83-87. doi: 10.1016/j.cbpa.2008. 09.034

Rajesh, G., Mishra, S. R., Paul, A., Punetha, M., Vidyalakshmi, G. M., Narayanan, K., et al. (2018). Transcriptional and translational abundance of bone morphogenetic protein (BMP) 2, 4, 6, 7 and their receptors BMPR1A, 1B and BMPR2 in buffalo ovarian follicle and the role of BMP4 and BMP7 on estrogen production and survival of cultured granulosa cells. Res. Vet. Sci. 118, 371-388. doi: 10.1016/j.rvsc.2018.04.002

Ramirez, G., Palomino, J., Aspee, K., and De los Reyes, M. (2020). GDF-9 and BMP15 mRNA levels in canine cumulus cells related to cumulus expansion and the maturation process. Animals 10:462. doi: 10.3390/ani10030462

Rodriguez-Chanfrau, J. E., Rodriguez-Riera, Z., and Gamiotea-Turro, D. (2019). Trimethylchitosan hydrochloride obtained from lobster carapace chitin on a bench scale. Biointerface Res. Appl. Chem. 9, 4279-4283. doi: 10.33263/ BRIAC95.279283

Rosen, V. (2009). BMP2 signaling in bone development and repair. Cytokine Growth Factor Rev. 20, 475-480. doi: 10.1016/j.cytogfr.2009.10.018

Shimasaki, S., Moore, R. K., Otsuka, F., and Erickson, G. F. (2004). The bone morphogenetic protein system in mammalian reproduction. Endocr. Rev. 25, 72-101. doi: 10.1210/er.2003-0007
Shu, L., Yang, Y. N., Huang, H. Y., and Ye, H. H. (2016). A bone morphogenetic protein ligand and receptors in mud crab: a potential role in the ovarian development. Mol. Cell. Endocrinol. 434, 99-107. doi: 10.1016/j.mce.2016. 06.023

Wang, C., and Roy, S. K. (2009). Expression of bone morphogenetic protein receptor (BMPR) during perinatal ovary development and primordial follicle formation in the hamster: possible regulation by FSH. Endocrinology 150, 1886-1896. doi: 10.1210/en.2008-0900

Wang, X., Su, L., Pan, X., Yao, J., Li, Z., Wang, X., et al. (2015). Effect of BMP-6 on development and maturation of mouse preantral follicles in vitro. Biotechnol. Biotechnol. Equip. 29, 336-344. doi: 10.1080/13102818.2014.996605

Xiao, Y. T., Xiang, L., and Shao, J. Z. (2007). Bone morphogenetic protein. Biochem. Biophys. Res. Commun. 362, 550-553. doi: 10.1016/j.bbrc.2007.08.045

Yang, T., Wei, B. H., Hao, S. L., Wei, Y. L., and Yang, W. X. (2020). Bone morphogenetic protein 2 (BMP2) mediates spermatogenesis in Chinese mitten crab Eriocheir sinensis by regulating kinesin motor KIFC1 expression. Gene 754:144848. doi: 10.1016/j.gene.2020.144848

Yang, Y. N., Lin, D. D., Bao, C. C., Huang, H. Y., and Ye, H. H. (2019). Serotonergic mechanisms of oocyte germinal vesicle breakdown in the mud crab, Scylla paramamosain. Front. Physiol. 10:797. doi: 10.3389/fphys.2019.00797

Yang, Y. N., Shu, L., Jiang, Q. L., Huang, H. Y., and Ye, H. H. (2018). Does the bone morphogenetic protein 7 inhibit oocyte maturation by autocrine/paracrine in mud crab? Gen. Comp. Endocrinol. 26, 119-125. doi: 10.1016/j.ygcen.2018. 05.004

Yang, Y. N., Zhang, Y., Zhuang, Y., Zhang, C. Y., Bao, C. C., and Cui, Z. X. (2021). Identification of differentially abundant mRNA transcripts and autocrine/paracrine factors in oocytes and follicle cells of mud crabs. Anim. Reprod. Sci. 230:106784. doi: 10.1016/j.anireprosci.2021.106784

Yonge, C. M. (1926). Structure and physiology of the organs of feeding and digestion in Ostrea edulis. J. Mar. Biol. Assoc. U.K. 14, 295-386. doi: 10.1017/ S002531540000789x

Conflict of Interest: The authors declare that the research was conducted in the absence of any commercial or financial relationships that could be construed as a potential conflict of interest.

Publisher's Note: All claims expressed in this article are solely those of the authors and do not necessarily represent those of their affiliated organizations, or those of the publisher, the editors and the reviewers. Any product that may be evaluated in this article, or claim that may be made by its manufacturer, is not guaranteed or endorsed by the publisher.

Copyright (c) 2021 Yang, Zhang, Cui and Bao. This is an open-access article distributed under the terms of the Creative Commons Attribution License (CC BY). The use, distribution or reproduction in other forums is permitted, provided the original author(s) and the copyright owner(s) are credited and that the original publication in this journal is cited, in accordance with accepted academic practice. No use, distribution or reproduction is permitted which does not comply with these terms. 